\title{
Prolegómenos al estudio de la literatura memorialística de los refugiados españoles de 1939 en Argelia
}

\author{
Santiago Navarro Pastor \\ Heinrich-Heine-Universität (Düsseldorf) \\ orcid.org/0000-0001-8696-1053
}

Presentación: 16 dic. 2019 | Aceptación: 8 abril 2020 | Publicación: 31 oct. 2020

Cita recomendada: Navarro Pastor, Santiago. 2020. «Prolegómenos al estudio de la literatura memorialística de los refugiados españoles de 1939 en Argelia». Dictatorships \& Democracies. Journal of History and Culture 8: 187-211. doi: https://dx.doi.org/10.7238/dd.voi8.3173

Resumen: Este artículo se centra en la literatura testimonial elaborada por quienes abandonaron España al final de la Guerra Civil española en 1939 y se establecieron accidentalmente en la Argelia francesa, donde muchos de ellos afrontaron experiencias en campos de internamiento como trabajadores forzados. En el trabajo se caracteriza sumariamente este corpus, que abarca unos treinta títulos, la mayoría de los cuales son obra de escritores no profesionales. En segundo lugar, se presta atención a un ejemplo de esta literatura, las memorias de Carlos Jiménez Margalejo (2008), con el objeto de destacar su singularidad dentro de este grupo de textos, escritos en su mayoría en español o francés.

Palabras clave: exilio español, 1939, Argelia, Alicante, Orán, Stanbrook, literatura testimonial, autobiografía, experiencia concentracionaria, memorias, cautiverio, campos de internamiento, Djelfa, Max Aub, Carlos Jiménez Margalejo, Antonio Martínez López, José Muñoz Congost, Antonio Blanca, Segunda Guerra Mundial

\section{Prolegomena to the Study of the Testimonial Literature of Spanish Refugees in} Algeria (1939)

Abstract: This paper focuses on the testimonial literature created by those who left Spain at the end of the Spanish Civil War in 1939 and accidentally settled in French Algeria, where many of them were subject to forced labor in internment camps. An effort will be undertaken to summarily describe this corpus that includes about thirty titles, most of which were written by non-professional authors. As a second aim, some attention will be brought to one example of this literature, namely the memoirs of Carlos Jiménez Margalejo (2008), in an attempt to underline its singularity within this group of texts, written mostly in Spanish or French.

Keywords: Spanish exile, 1939, Algeria, Alicante, Oran, Stanbrook, testimonial literature, autobiography, concentration camps experience, memoirs, captivity, internment camps, 
Djelfa, Max Aub, Carlos Jiménez Margalejo, Antonio Martínez López, José Muñoz Congost, Antonio Blanca, World War II

Los últimos días de octubre de 2019 se celebró en Argel y Orán, organizado por la Embajada Española y el Instituto Cervantes, el seminario titulado Memoria del exilio español en Argelia. Este encuentro vino precedido, dos años antes, por unas Jornadas Internacionales sobre el Exilio Republicano de 1939 en Argelia, que tuvieron lugar en la Universitat Autònoma de Barcelona en abril de 2017. ${ }^{1}$ Se mencionan aquí dos simposios recientes, programados cuando contamos ya con un aporte abundante de conocimientos sobre la materia específica del exilio español de 1939 en el norte de África. Ese conjunto de contribuciones requiere una recapitulación o sistematización crítica, un primer balance académico. Las líneas que siguen, obviamente, no pueden ofrecer este arduo trabajo de síntesis. Se centrarán en un sector específico de ese campo, el de la literatura memorialística, con el ánimo de brindar una panorámica bibliográfica que pueda servir, en definitiva, de incitación a su estudio.

I

La literatura memorialística de los refugiados republicanos españoles de 1939 en el norte de África, y especialmente en Argelia, presenta hasta ahora una treintena larga de títulos. Con toda seguridad, existe aún material inédito, y de hecho algunas piezas de este acervo van publicándose de cuando en cuando en forma de libro o divulgándose en revistas y publicaciones especializadas. En conjunto, se trata de un ramillete de obras muy desiguales, que, por lo general, no se deben a escritores profesionales. A diferencia de otros exponentes del exilio republicano de 1939 (o del de 1936, o de quienes se expatriaron en el transcurso de los tres años de Guerra Civil), en contraste con no pocos exiliados que recalaron en centros universitarios estadounidenses, de México u otros países de Iberoamérica,

1 El número 20 de la revista Laberintos $(2018,187-392)$ reúne, en una sección especial titulada $E l$ exilio republicano en Argelia, las ponencias presentadas en aquel encuentro. 
o en la propia Francia metropolitana, en el caso de los que llegan a Argelia en marzo de 1939 predomina el testimonio de firmas prácticamente desconocidas. El escritor Max Aub constituye una excepción a esta norma y es indiscutiblemente la figura que mayor interés ha suscitado hasta el momento entre estos autores establecidos en el espacio magrebí: por el hecho de que haya dejado literatura de creación sobre su etapa en el campo de internamiento argelino de Djelfa (Aub 1944, 1955, 1963, 1965) y por la trascendencia del autor para la literatura en lengua española.

Los ejemplos más característicos de esta familia de textos (Mercadal 1983; Muñoz Congost 1989; Beltrán 1989; Lizcano 1989, 1991; Blanca 1991, 2018; Martínez López 2004, 2006; González Beltrán 2006; Jiménez Margalejo 2008) se difundieron entre los años ochenta del siglo xx y la primera década del XXI, si bien se publicaron testimonios tempranos desde los cuarenta en el exilio (Cabezas 1940; Palencia 1946; Castillo 1956; Esteve 1957). Otros empezaron a conocerse en los sesenta, primero en el extranjero (Vilanova 1969) y, desde principios de los setenta, en España (Baldó 1970, 1973, 1977). Su recuento es todavía una tarea en marcha, como revela el censo que vienen realizando los hispanistas franceses Bernard Si$\cot (2008,2010)$ y Joël Delhom (2009). Se trata de un corpus de escritos primordialmente en español, también en francés (Martínez López 2004; Blanca 2002, 2014) y en menor número en catalán (Ros i Martí 1989, 1991). Nos encontramos comprensiblemente ante obras de escasa circulación y, con salvedades, publicadas por editoriales sin apenas visibilidad, incluidas las patrocinadas por instituciones oficiales. En ocasiones, son ediciones de autor o ligadas a asociaciones políticas o culturales de radio de acción bastante limitado.

En el ámbito académico, esta literatura apenas ha recibido atención hasta hace poco por parte de la filología y los estudios culturales. Contamos ya, eso sí, con dos sólidos monografías: Nadia Bouzekri (2012) y Danae Gallo González (2018a). La literatura memorialística ha sido leída, como es lógico, en su función ancilar de documento-fuente para los historiadores. De hecho, en el caso específico del exilio en Argelia, el relativo auge de estas publicaciones a partir de los ochenta se vio favorecido por la iniciativa de los especialistas en historia contemporánea, concretamente después de la aparición de un artículo del catedrático de la 
Universidad de Murcia Juan Bautista Vilar que hizo época: «Relación nominal de los militantes republicanos evacuados de Alicante por el buque inglés Stanbrook con destino a Orán en 28 de marzo de 1939» (Vilar 1983). Ese nombre, el del carguero Stanbrook, uno de los últimos barcos que abandonaron los puertos españoles del Mediterráneo con refugiados en los días finales de la Guerra Civil, se ha convertido, en el transcurso de los últimos tres decenios, en una referencia constante en todo lo que guarda relación con el exilio de los republicanos españoles en el norte de África: el nombre del barco y su imagen se difunden en publicaciones de varia índole, en entregas académicas y periodísticas, en documentales televisivos y radiofónicos (Sella 2006; Albert 2012; Murga 2016), en exposiciones (Barciela \& Ródenas 2016) y en ejemplos de novela gráfica incluso (Roca 2010). La lista de pasajeros del buque británico se reproduce en más de una decena de libros, y fotos de la embarcación repleta de emigrados figuran en la portada de numerosísimos impresos. Estamos ante un singular fenómeno memorial, que se ha revelado como un asunto de gran fecundidad. Todo ello tiene en buena medida su punto de arranque en la investigación archivística del historiador Vilar, que encuentra en los Archivos Nacionales de Ultramar de Francia, en Aix-en-Provence, la lista en cuestión, dando inicio a una cadena de trabajos que han ido iluminando la cuestión desde el campo de la historiografía y propiciando, asimismo, la aparición de un abundante número de memorias personales, familiares, de organizaciones políticas, etc. Estas aportaciones están restituyendo una imagen cada vez más completa de un episodio histórico que no era el más conocido en el cuadro de los estudios sobre el exilio español vinculado a la Guerra Civil. No era esa, desde luego, la primera ocasión en que se leía en letras impresas el nombre del Stanbrook. Ya en la obra pionera de Antonio Vilanova, Los olvidados (1969), se pudieron ver testimonios de refugiados de aquella evacuación de marzo de 1939. Y, aun antes de la muerte de Franco, el periodista Eduardo de Guzmán publicó en Madrid la parte inicial de un extenso ciclo autobiográfico, La muerte de la esperanza (Guzmán 1973). En ella se hablaba de la salida del barco y de la experiencia de aquellos a los que se llamó «náufragos del Stanbrook», esto es, del drama que vivieron en el puerto de Alicante quienes quedaron a la espera de unos buques que nunca llegaron después del 28 de marzo, entre 
ellos el propio Guzmán. Tanto la partida del barco como la tragedia del puerto en los días finales de la guerra fueron objeto de un extenso reportaje de este mismo escritor, publicado en 1976 en el semanario Triunfo (Guzmán 1976). A este segundo asunto dedicó también un documentado trabajo académico Aline Santonja (1984) en fechas cercanas al artículo seminal de Vilar. Justo es recordar, asimismo, el primer título autónomo importante sobre la experiencia concentracionaria española en el Magreb, Internamiento y resistencia de los republicanos españoles en África del Norte durante la Segunda Guerra Mundial, libro colectivo aparecido en España poco antes, elaborado a partir de testimonios de refugiados que pasaron por los campos de internamiento franceses de Argelia, Túnez y Marruecos (Santiago, Lloris \& Barrera 1981). Como sea, la colaboración entre labor historiográfica y aporte testimonial no necesita de muchas justificaciones. La constitución de los saberes históricos y culturales es un proceso lento y colaborativo en que carece de sentido establecer fronteras disciplinarias rígidas. Aquí solo se ha querido hacer referencia a un ejemplo de influjo mutuo entre disciplinas. A este respecto, se deja constancia de la manera en que la investigación historiográfica ha actuado de estímulo, dando pie a un filón de literatura testimonial que, a su vez, retroalimenta la tarea de los historiadores, capacitados para aquilatar — con un tipo de conocimiento diferente al del testigo- una materia, como la memorialística, que necesita del foco crítico de la ciencia histórica y, en general, de las humanidades.

En este trabajo se plantea una tentativa de tipificación de esta producción, sobrevolándola, y se dedican, por último, algunas consideraciones a una muestra, las Memorias de un refugiado español en el norte de África, 1939-1956, de Carlos Jiménez Margalejo (2008), que ocupa un puesto importante dentro de esta colectánea. 


\section{Cuadro 1. Corpus de textos memorialísticos por décadas y países}

\begin{tabular}{|c|c|c|c|}
\hline $\begin{array}{l}\text { Década } \\
1940\end{array}$ & $\begin{array}{l}1943 \\
1944 \\
1946\end{array}$ & $\begin{array}{l}\text { Cabezas, Felipe A. «Viaje épico. Los expatriados del } \\
\text { Stanbrook» } \\
\text { Aub, Max. «iYo no invento nada!» } \\
\text { Aub, Max. Diario de Djelfa } \\
\text { Palencia, Isabel de. Smouldering Freedom... }\end{array}$ & $\begin{array}{l}\text { CU } \\
\text { MX } \\
\text { UK }\end{array}$ \\
\hline $\begin{array}{l}\text { Década } \\
1950\end{array}$ & & $\begin{array}{l}\text { Aub Max. «El limpiabotas del Padre Eterno» } \\
\text { Esteve, Arturo. Búsqueda en la noche }\end{array}$ & \\
\hline $\begin{array}{l}\text { Década } \\
1960\end{array}$ & $\begin{array}{l}1963 \\
1965 \\
1968 \\
1969\end{array}$ & $\begin{array}{l}\text { Aub, Max. «El cementerio de Djelfa» } \\
\text { Aub, Max. Historias de mala muerte } \\
\text { Ros, Antonio. Horas de angustia y esperanza } \\
\text { Vilanova, Antonio. Los olvidados }\end{array}$ & $\begin{array}{l}\text { ES } \\
\text { MX } \\
\text { MX } \\
\text { FR }\end{array}$ \\
\hline $\begin{array}{l}\text { Década } \\
1970\end{array}$ & $\begin{array}{l}1970 \\
1972 \\
1974 \\
1976 \\
1976 \\
1977\end{array}$ & $\begin{array}{l}\text { Baldó, Ricardo. Un cuento escrito en la arena } \\
\text { Baldó, Ricardo. Del negro al amarillo. Relatos del exilio } \\
\text { Hernández Tomás, Jesús. Yo fui un ministro de Stalin } \\
\text { Mera, Cipriano. Guerra, exilio y cárcel de un } \\
\quad \text { anarcosindicalista } \\
\text { Ros, Antonio. Diario de un refugiado republicano } \\
\text { Baldó, Ricardo. Exiliados españoles en el Sahara, 1939-1943 }\end{array}$ & $\begin{array}{l}\text { ES } \\
\text { ES } \\
\text { ES } \\
\text { ES } \\
\text { ES } \\
\text { ES }\end{array}$ \\
\hline $\begin{array}{l}\text { Década } \\
1980\end{array}$ & $\begin{array}{r}1989 \\
1989\end{array}$ & $\begin{array}{l}\text { Internamiento y resistencia de los republicanos españoles en } \\
\text { África del Norte } \\
\text { Mercadal Bagur, Deseado. Yo estuve en Kenadza. Nueve años } \\
\text { de exilio } \\
\text { Ros i Martí, Germinal. «Els camps de concentració a l'Àfrica } \\
\text { del Nord...» } \\
\text { Ros i Martí, Germinal. Anys negres. Crònica lliure dels anys } \\
\text { de guerra, 1939-1945 } \\
\text { Muñoz Congost, José. Por tierras de moros. El exilio español } \\
\text { en el Magreb } \\
\text { Soriano, Antonio. Éxodos. Historia oral del exilio } \\
\text { republicano en Francia } \\
\text { (2016). Beltrán Alcaraz, Isabel. 'Stanbrook'. Vivencias de un } \\
\text { exilio }\end{array}$ & $\begin{array}{l}\text { ES } \\
\text { ES } \\
\text { ES } \\
\text { ES } \\
\text { ES } \\
\text { ES } \\
\text { ES }\end{array}$ \\
\hline $\begin{array}{l}\text { Década } \\
1990\end{array}$ & 1991 & $\begin{array}{l}\text { Lizcano, Conrado. «Crónica en vivo de los exiliados } \\
\text { españoles en el norte de África» } \\
\text { Ros i Martí, Germinal. «El començament de l'exili. Anys } \\
\quad \text { negres...» } \\
\text { Blanca, Antonio. Cuaderno del destierro (fragmentos) }\end{array}$ & $\begin{array}{l}\text { ES } \\
\text { ES }\end{array}$ \\
\hline
\end{tabular}




\begin{tabular}{|c|c|c|c|}
\hline \multirow{10}{*}{$\begin{array}{l}\text { Década } \\
2000\end{array}$} & 2002 & Blanca, Antoine. Itinéraires d'un républicain espagnol & FR \\
\hline & 2002 & Escudero Galante, Francisco. Pasajero $2058^{*}$ & ES \\
\hline & 2003 & Gonzalez, Georges. Mais l'Algérie vivra toujours & FR \\
\hline & 2004 & Martínez López, Miguel. Casbah d’oubli... & FR \\
\hline & 2006 & Martínez López, Miguel. Alcazaba del olvido...** & ES \\
\hline & 2006 & $\begin{array}{l}\text { González Beltrán, Helia, y Alicia González Beltrán. Desde la } \\
\text { otra orilla. Memorias del exilio }\end{array}$ & ES \\
\hline & 2007 & Marco Botella, Antonio. La odisea del 'Stanbrook' & ES \\
\hline & 2008 & $\begin{array}{l}\text { Jiménez Margalejo, Carlos. Memorias de un refugiado } \\
\text { español en el norte de África }\end{array}$ & $\begin{array}{l}\text { ES } \\
\text { ES }\end{array}$ \\
\hline & 2009 & Cuesta Suárez, Nieves. Simplemente mi vida & ES \\
\hline & 2009 & $\begin{array}{l}\text { Alonso Sellés, José. Desde la otra orilla. Recuerdos de un niño } \\
\text { exiliado }\end{array}$ & \\
\hline \multirow[t]{7}{*}{$\begin{array}{l}\text { Década } \\
2010\end{array}$} & 2014 & $\begin{array}{l}\text { Blanca, Antoine. Les trois voyages d'Abel, fils de républicain } \\
\text { espagnol }\end{array}$ & $\begin{array}{l}\text { FR } \\
\text { ES }\end{array}$ \\
\hline & 2014 & Gassó, Laura. Diario de Gaskin & ES \\
\hline & 2014 & Beneyto Poveda, Milagros. Desterrados & ES \\
\hline & 2016 & Camacho Samper, Yénia. De Orán y del regreso & ES \\
\hline & 2016 & Serna Alba, Ricardo. Diario de Orán*** & FR \\
\hline & 2016 & $\begin{array}{l}\text { Espinós Beviá, Antonieta. 2016. jYa se va el vapor! } 19 \text { de } \\
\quad \text { marzo de 1939... }\end{array}$ & ES \\
\hline & 2018 & $\begin{array}{l}\text { Blanca, Antonio. Diario de Antonio Blanca (campos de } \\
\text { Argelia 1939) }\end{array}$ & \\
\hline
\end{tabular}

* La obra se reedita en 2006 con el título El último barco del exilio.

** Es la versión española del título de 2004 del mismo autor.

*** Editado por Ricardo Montes Bernárdez, José A. Sánchez Hernández y Enrique Serna Rodríguez en el volumen Ricardo Serna Alba y «El Liberal». Exilio en Orán. Murcia: Colegio de Periodistas 2016.

En el cuadro anterior figura un recuento, sin ánimo exhaustivo, de los textos memorialísticos que acreditan experiencias de refugiados españoles en Argelia. Su presentación tabular persigue mostrar con alguna precisión la distribución temporal de estas aportaciones. Es innegable, a primera vista, la abundancia de títulos que ha habido en los dos últimos decenios, aunque también llaman la atención los exponentes del género publicados en España en décadas anteriores. Este aluvión memorial no comienza, pues, en los últimos años, después de que supuestamente la generación de los nietos hubiera desatado finalmente el nudo gordiano que había impedido hasta hace cuatro días la libre expresión sobre este 
asunto. Este elenco de publicaciones, que se inicia relativamente pronto, enlaza, además, desde la década de 1970, con la larga batería de estudios generales sobre el exilio (Abellán 1976; Rubio 1977; Rafaneau-Boj 1995; Dreyfus-Armand 1999, por citar solo algunos). Esta plétora de obras (estudios y memorias), editadas algunas incluso antes del final del franquismo y que sin duda esperan aún una lectura atenta, atestigua un interés, un esmero y un respeto por la cuestión del exilio que no se compadecen con la supuesta existencia de un pacto de olvido o silencio sobre esta materia en los años de la Transición.

\section{II}

Este caudal de testimonios se ha ido vertiendo por cauces muy diversos. Caracterizando a vuelapluma este corpus de memorias, podrían fijarse las siguientes categorías, que no deben tomarse como compartimentos estancos.

Literatura de creación. Se ha hecho referencia al inicio de estas notas a Max Aub, quien en su poemario Diario de Djelfa (1944) y en varios relatos dio la versión literaria que más ha circulado sobre los campos de internamiento y de trabajo franceses en Argelia. Otros dos autores que, al igual que Aub, reelaboran experiencias similares en entregas con voluntad literaria son Arturo Esteve en su novela Búsqueda en la noche (1957) y Ricardo Baldó en tres colecciones de relatos publicadas en España en los setenta: Un cuento escrito en la arena (1970), Del negro al amarillo (1973) y, pese a su título aparentemente ensayístico, Exiliados españoles en el Sahara, 1939-1943 (1977). Las agrupaciones que siguen se refieren, por el contrario, a contribuciones en prosa de enfoque autobiográfico y que, con una sola excepción, no se presentan como textos de creación.

Testimonio en libros de historia. La actividad memorialística se enmarca inicialmente, como queda dicho, en monografías de historia. Es el caso del estudio de Vilanova, Los olvidados (1969), y de Éxodos. Historia oral del exilio republicano en Francia, de Antonio Soriano (1989). Son testimonios que responden, por lo general, a una entrevista oral grabada o resultan de la contestación por escrito a un formulario planteado por un historiador. Algo similar puede verse en las exposiciones, más extensas, que se DICTATORSHIPS \& DEMOCRACIES 8 (2020) · E-ISSN: 2564-8829 - PUNCTUM, UNIVERSITAT OBERTA DE CATALUNYA \& FUNDACIÓ CARLES PII SUNYER 
integran en números de revistas dedicados al asunto del exilio. Es el caso de Laberintos (2018) o el del monográfico de la revista Canelobre (1991), Alicantinos en el exilio, que reúne varios textos de refugiados en Argelia, difundidos en parte previamente, de Conrado Lizcano (1989), Germinal Ros i Martí (1989) y José Muñoz Congost (1989).

Testimonio extenso en libro: memorias de comunidad política. Esta literatura testimonial se emancipa, por su extensión, del manual de historia o de la revista especializada y se configura en libro. En este apartado, cabe mencionar el ya citado libro colectivo Internamiento... (Santiago, Lloris \& Barrera 1981), de inspiración comunista; títulos como el de Deseado Mercadal, periodista menorquín que militó en el socialismo, Yo estuve en Kenadza. Nueve años de exilio (1983); el de José Muñoz Congost, Por tierras de moros. El exilio español en el Magreb (1989), o el de Miguel Martínez López, Alcazaba del olvido..., en francés (2004) y en español (2006). En estas obras, se integran, junto al relato autobiográfico, testimonios de otros internados en campos argelinos, o bien se encuentra una galería de retratos de miembros de la comunidad política en que se inscribe el autor. De ese modo, con la descripción de un conjunto amplio de gentes, la publicación adquiere un carácter misceláneo. Los dos últimos nombres representan al llamado «movimiento libertario español», del que se traza un retrato-homenaje y se documentan sus actividades en el norte de África. En este campo del testimonio de fuerte impronta política, pero sin ánimo de rendir tributo a una comunidad en particular, se hablará más adelante de las memorias de Carlos Jiménez Margalejo (2008).

Memorias familiares. A diferencia del apartado anterior, los exponentes de esta sección dan cuenta de un tipo de memoria más privada. Son retratos de familia en que las declaraciones de índole política ceden paso a consideraciones de orden más personal. Contienen el relato de los avatares de un grupo familiar trasplantado a tierras argelinas, testimonio no forzosamente ajeno a las notas ideológicas de afirmación y solidaridad genérica con la causa republicana. Son característicos de esta sección el libro de Isabel Beltrán, 'Stanbrook'. Vivencias de un exilio (1989); el de sus hijas Helia y Alicia González Beltrán, Desde la otra orilla. Memorias del exilio (2006); y el casi homónimo de Alonso Mallol, Desde la otra orilla. Recuerdos de un niño exiliado (2009). Cabría, asimismo, situar en este 
grupo los textos de la familia de Antonio Blanca, sobre los que se volverá brevemente, no obstante, en otros apartados.

Diarios. No son muchos los diarios de exiliados que se conservan (o que se han dado a conocer hasta ahora). Los tres más extensos son el del aviador republicano Antonio Gassó, preparado para la edición por su hija Laura (Gassó 2014); el del periodista alicantino Antonio Blanca, publicado fragmentariamente en España (Blanca 1991), aparecido años después en versión íntegra traducido al francés (Blanca 2009) y en su original español, en una edición cuidada por Bernard Sicot y Danae Gallo González (Blanca 2018), y el del periodista murciano Ricardo Serna (2016). El diario, por su capacidad de sugerir una mayor cercanía a los hechos, posee un poder icástico y presupone un marco de confidencialidad que lo singularizan frente a otros textos de naturaleza memorialística.

Novelización del testimonio. La reelaboración de testimonios previamente existentes, subsumidos en un nuevo conjunto en formato de novela, es otra modalidad de este conjunto de textos. Ejemplos notables de ello son dos contribuciones del diplomático francés Antoine Blanca, hijo del exiliado español Antonio Blanca, recién mencionado. Antoine Blanca es autor de Itineraires d'un républicain espagnol (2002), texto a medio camino entre la novela y el testimonio en que se trasfunden los diarios de su padre en una vaga trama novelística. A Blanca hijo debemos también un segundo título de enfoque similar: Les trois voyages d'Abel, fils de républicain espagnol (2014). En forma novelística se encuentran muestras de la segunda generación de exiliados, al igual que aportaciones de nietos de los refugiados de 1939, que, residiendo en España y al calor del llamado «movimiento de recuperación de la memoria histórica», ofrecen su contribución al género. Basten dos apuntes: Pasajero 2058 (en referencia al número de uno de los ocupantes del Stanbrook), del periodista Francisco Escudero (2002), ${ }^{2}$ una especie de memorias noveladas, y Desterrados, de Milagros Beneyto Poveda (2014), narración en que se reescriben las memorias del abuelo de la autora, Antonio Poveda Sanjuán, uno de los escritores inéditos a los que se aludió al inicio de estas notas.

2 Reeditado con el título de El último barco del exilio (2006). 
Epistolarios. Se está empezando a estudiar con criterio académico la correspondencia de algunos exiliados. En este apartado, presentan interés especial algunos repertorios epistolares que, por no haber sido concebidos para su envío postal inmediato, asumen carácter de diario. Es el caso del epistolario de José Sánchez Candela, estudiado por Cayetano Mas (2012). La expresión fluye en ellos sin las cortapisas de la autocensura y sin tener que recurrir a las estrategias de expresión elusiva, trueques de personalidad incluso, que se ven en la correspondencia inédita de otros exiliados en Argelia, que temen justificadamente la fiscalización de sus cartas por parte de la censura postal franquista o la francesa.

La clasificación anterior establece seguramente distinciones que podrían reorganizarse de otro modo. Es obvio que una división fundamental pasa por agrupar, de una parte, aquellos textos memorialísticos de quienes, pese a las penosas condiciones del exilio, afortunadamente no hubieron de pasar por el duro trance de los campos de trabajo y, por otra parte, las memorias de aquellos refugiados varones que sí lo hicieron, esto es, varios miles de entre los más de 10 ooo refugiados en que se cifra el número de exiliados llegados a Argelia durante el mes de marzo de 1939 (Alted Vigil 2005). Un criterio razonable en los trabajos acerca del exilio español de 1939 aconseja, por lo demás, el escrutinio diferenciado (o comparado) de los testimonios de la primera y la segunda generaciones de refugiados. A ello sigue, como sector que obviamente requiere un examen aparte, el de las reelaboraciones recientes de esa memoria por parte de integrantes de la tercera y la cuarta generaciones, o simples interesados en la materia que, por edad, se equiparan a las generaciones de nietos y bisnietos de los refugiados. En última instancia, un conocimiento solvente de esta cuestión exige una atención particular a cada texto, puesto que en este corpus la casuística es verdaderamente amplia. Eso no debería estar reñido con la aplicación de la norma heurística recomendada por Javier Sánchez Zapatero (véase la bibliografía) de abordar la experiencia concentracionaria como un fenómeno universal (y lo mismo podría decirse del exilio en general), sin dejar de tener en cuenta por ello las peculiaridades geográficas, generacionales, de género, de duración del periodo de destierro o de otro tipo, o posibles configuraciones míticas (o de otra índole) del discurso testimonial (Penef 1988). Es evidente, además, que en el estudio 
de esta materia es fundamental abandonar toda tentación de enfoque reverencial, preservando la independencia de criterio y la distancia crítica frente a lo que pueda estipular la agenda política de cada momento en cuanto a memoria oficial.

\section{III}

Las Memorias de un refugiado español en el Norte de África, 1939-1956, de Carlos Jiménez Margalejo (2008), ${ }^{3}$ son un documento excepcional dentro de esta producción. Lo son por su extensión y detalle (alrededor de cuatrocientas densas páginas), así como por su grado de autoconciencia (en lo psicológico, en lo ideológico) y por el rico análisis personal, colectivo e histórico que brindan. Las Memorias son la segunda parte de un volumen publicado en 2002, Los que teníamos dieciocho años, que el autor presenta como relato, según reza el prefacio, «hilvanado con la licencia de la novela» (Jiménez Margalejo 2002, 5). La primera entrega versa, en lo esencial, sobre su intervención en la Guerra Civil española como oficial del ejército de la República. Las Memorias conectan directamente con ese primer título; así, las páginas finales del libro de 2002 se reproducen, sin cambios, al inicio del de 2008. Nada distingue en su entonación y modo de narrar el primer tomo del segundo, en lo relativo al menos al punto de vista adoptado, que es el de la primera persona característica de un texto confesional.

Estos dos amplios conjuntos, escritos en Venezuela a partir de 1963, representan un extraordinario ejercicio de escritura. Asombra en ellos, en primer término, una memoria prodigiosa, capaz de evocar lo vivido, en ocasiones casi día a día, con gran precisión y a más de veinte años de distancia; en segundo término, una admirable capacidad de verbalización de ese turbión de vivencias y sucesos. Es cierto que no todo en ellos deriva de la facultad memorística y se entretejen ahí componentes de otra naturaleza: abundante información histórica, momentos de reflexión personal de orden político o ideológico, la mostración de un amplio espectro de estados de ánimo (lo que imprime a su discurso una fuerte impronta

3 Se han ocupado de la obra ante todo Bouzekri (2012, 136-137), Sicot (2015b, 28-30) y con más detenimiento Gallo González (2018a, 207-281). 
emocional). Pese a tal diversidad de elementos, el espesor, la viveza y la minuciosidad de lo expuesto en cuanto a experiencia estrictamente personal son impresionantes y hacen pensar en un testigo veraz, dueño de una retentiva excepcional. El manifiesto desinterés por transmitir una imagen heroica de aquellas vivencias recalca, además, la sensación de autenticidad.

Las Memorias se desenvuelven en dos planos: el de la descripción del proceso personal que afronta el autor desde el final de la Guerra Civil hasta 1956 (un dificilísimo iter vital expuesto en términos muy poco autocomplacientes) y el de las convulsiones políticas e históricas de ese periodo. De hecho, el libro va ilustrando, con una notable capacidad reflexiva, la huella del proceso histórico en el personal, un desarrollo expuesto de forma pormenorizada y con todo el dinamismo y la complejidad que ignoramos hoy en día cuando, incurriendo en una simplificación teleológica, nos referimos a la Segunda Guerra Mundial como aquella guerra en que una alianza de países vence felizmente a las potencias del Eje. El friso histórico que ofrece Margalejo, en especial el relativo a los años de la conflagración mundial, lo vemos bullir ante nuestros ojos con el grado de incertidumbre sobre su desenlace que es propio de quien está siguiendo con zozobra unos acontecimientos cuyo final desconoce y en los que se juega mucho. En ese aspecto, su discurso está dotado de los atributos de suspense y emoción de una obra narrativa que sabe administrar con eficacia la indeterminación de su punto de llegada.

Estas Memorias se leen, pues, en cierto modo como un manual de historia, dado que se vertebran en gran medida al galope de los avatares políticos de aquellos años tan procelosos y de la repercusión de orden psicológico, moral e ideológico que tienen en la vida del autor. No hay en ello, obviamente, un rasgo de absoluta novedad, pues esa práctica obedece a las reglas del género. Aquellos sucesos son, resumiendo: el fin de la Guerra Civil y la implantación general del régimen franquista, el pacto germano-soviético de agosto de 1939, el ataque alemán a Polonia y el inicio de la Segunda Guerra Mundial, el armisticio de junio de 1940 y el establecimiento del régimen de Vichy, la Operación Barbarroja, el desembarco aliado en el norte de África en noviembre de 1942, la gradual neutralización de Vichy en Argelia, la conclusión del conflicto mundial en 1945 y el proceso independentista en Marruecos. Este acontecer de la historia 
externa tiene un impacto interior en la exposición de la aventura personal del refugiado: su evacuación desde Alicante a Orán, con el relato del penoso período de obligada permanencia de varias semanas a bordo del Stanbrook; la estancia, en régimen semicarcelario, en dos centros de albergue para refugiados (primero en Orán y después en Boghari, al sur de Argel); su ingreso forzoso en las Compañías de Trabajadores Extranjeros (CTE) con la entrada de Francia en la guerra en septiembre de 1939; su traslado al campo de Colomb-Béchar para trabajar en la construcción del ferrocarril transahariano; un período de castigo en una compañía disciplinaria; su paso, en 1943, al este de Argelia (región de Constantina), en la etapa de descomposición del régimen colaboracionista francés; su deserción de las CTE y establecimiento clandestino en Orán en 1944. Por último, la reseña del periodo de la posguerra mundial se concreta en una larga estancia en Casablanca, que concluye con su marcha a Venezuela luego de la independencia de Marruecos en 1956. En este trenzado de acontecimientos históricos y proceso biográfico personal, el autor consigue transmitir con gran plasticidad la fluctuante tesitura anímica (marcada primordialmente por la perplejidad, la indignación, la decepción, el desánimo, la angustia) en que va viéndose el protagonista en cada una de las fases mencionadas, cuya enumeración, simplificando, se refiere, en lo fundamental, al hecho de haber perdido la guerra, la deplorable reclusión en el Stanbrook (que puede entenderse como preludio de su experiencia concentracionaria posterior), la incomprensión ante la hostil acogida por parte de las autoridades francesas, el miedo a ser deportado a España, el agravamiento paulatino de la situación de los refugiados después del inicio de la guerra mundial, con el cortejo de desgracias que conlleva el paso por varios campos de trabajo, hasta la decepción final que significa la comprobación de que la derrota de las potencias del Eje no va a suponer la caída de Franco. En buena parte del libro, cada nueva página del decurso histórico tiene su reflejo elocuente en el estado de ánimo cada vez más sombrío del narrador.

A diferencia de las memorias de comunidad política a que se hacía referencia más arriba, en esta obra se constata un desamparo ideológico parejo al desvalimiento vital general que describen sus Memorias. La biografía de Margalejo es encuadrable en lo que en historiografía literaria 
llamamos «generación del 36» 0 «primera generación de posguerra», en la que abundan las trayectorias profesionales truncadas por la guerra. Ese elemento de vida mutilada, que, en rigor, puede aplicarse a cualquier exiliado, está muy presente en este volumen. En sus páginas se aprecia una orfandad radical, de la que el aspecto ideológico es únicamente una faceta más. Se menciona aquí solo por la insistencia con que de ello habla el autor. Sin constituir un caso único (podría aducirse también, a este propósito, el ejemplo de Arturo Esteve) ${ }^{4}$ la construcción ideológica de su testimonio difiere en ese sentido de otras muestras de este tipo. Todo él está traspasado por el empeño en cobrar espacios de independencia y libertad individual, tomando distancia con respecto a la facción política en que vivió integrado durante la Guerra Civil. Describe, en pocas palabras, un proceso de distanciamiento del movimiento comunista, concretamente de la hipoteca vital que implica la férrea obediencia que en aquellos años exige la militancia de ese signo. Tiene el libro no pocos remansos meditativos en que ofrece reflexiones muy expresivas sobre la mentalidad y conducta del militante comunista, para las que, según explica, solo encuentra parangón en el mundo de las vocaciones y el espíritu de abnegación del religioso convencido (Jiménez Margalejo 2008, 101 y passim).

Sintetizando, aun a costa de sacrificar muchas otras consideraciones importantes, podría decirse que, si la obra permite ser leída en esos dos estratos a los que se ha hecho referencia (el itinerario personal y el diorama histórico), las Memorias de Margalejo presentan una doble dimensión. Son, por una parte, un texto de fuerte carga emotiva, en lo que tiene de exposición dilatada del impacto sobre la personalidad de una lacerante experiencia de exilio y, en concreto, del paso por los campos de internamiento y de las lastimosas condiciones de vida y muerte en ellos. Las notas con que se retrata el autor (depauperación física e intelectual, aniquilación anímica y moral) son, desde luego, plenamente acordes con lo que sabemos a partir de la literatura concentracionaria. Por otro lado, las Memorias constituyen un documento histórico-político en que pueden distinguirse varios aspectos. Ante todo, se encuentra en el texto una

4 De hecho, Gallo González (2018, especialmente 234-282) dedica a ambos autores, haciendo una contraposición, penetrantes análisis realizados desde una perspectiva psicoanalítica. 
interpretación maximalista e internacionalizada de la Guerra Civil española en cuanto causa de salvación universal frente al nazismo y ocasión perdida por la comunidad de países democráticos, que en su lenidad con el hitlerismo se verán abocados a la guerra mundial (el clásico motivo de la denuncia de la no intervención). Junto a ello, el autor presta atención, desde una postura crítica, al proceso ideológico de los distintos grupos políticos españoles en el exilio, en especial al comunista; la voluntad de preservar su independencia personal y política, frente justamente a sus cofrades comunistas, no impedirá, pese a todo, que se retrate, en cierto modo, como su compañero de viaje. Comprensiblemente, hay también ráfagas de diatriba antifrancesa, expresada con una dureza que en algunos pasajes se modera en juicios más ecuánimes y desapasionados. Es perceptible una conciencia alerta ante el desarrollo de la política internacional (no solo en relación con España) durante y una vez finalizada la Segunda Guerra Mundial. Se advierte, asimismo, un esfuerzo por ponderar la situación interna española (concretamente, la represión franquista) en comparación con las condiciones de cautiverio en los campos de trabajo argelinos. Cuando el autor tiene ocasión de conocer, ya fuera de los campos, la vida de la Argelia francesa (y eso no ocurre hasta prácticamente 1944), aporta interesantes observaciones, contrastando la condición de la clase obrera argelina y la de la española. En lo relativo a la población nativa del Magreb, Jiménez Margalejo tiene una comprensión clara de la situación que conducirá a la emancipación política de Túnez, Marruecos y Argelia. Por último, la obra, como otros ejemplos de esta literatura, contiene algunos rudimentos de sociología de la Argelia colonial (singularmente, la descripción del mosaico de grupos de población que caracteriza a la Argelia de entonces) y algunos apuntes de índole antropológica sobre las comunidades musulmana y judía, vista en especial la primera con un desdén indisimulable.

Las Memorias de Carlos Jiménez Margalejo son, en suma, un documento muy destacado dentro del muestrario de textos presentados. Testimonio de una experiencia profundamente afligente, escrito con gran poder de elocuencia, ilustra de forma paradigmática una de las varias caras de aquel exilio español en el norte de África, que poco a poco va conociéndose con mayor detalle. 


\section{Bibliografía}

Abellán, José Luis, ed. 1976. El exilio español de 1939. Madrid: Taurus.

AA. VV. 2018. El exilio republicano en Argelia, dosier. Laberintos 20.

Albert, Aída, y Sonia Subirats, dir. 2012. Desde el silencio. Exilio republicano en el norte de África, documental. España: Rec Stop \& Play Producciones Audiovisuales.

Alonso Sellés, José. 2009. Desde la otra orilla. Recuerdos de un niño exiliado. Alicante: Instituto Alicantino de Cultura Juan Gil-Albert.

Alted Vigil, Alicia. 2005. La voz de los vencidos. El exilio republicano de 1939. Madrid: Aguilar.

Alted Vigil, Alicia, y Manuel Aznar Soler, ed. 1998. Literatura y cultura del exilio español de 1939 en Francia. Barcelona: AEMIC/GEXEL.

Aub, Max. 1955. «El limpiabotas del Padre Eterno». Cuentos ciertos, 255-364. México: Antigua Librería Robredo.

_. 1963. «El cementerio de Djelfa». Ínsula 204: 16. [También disponible en Historias de mala muerte, 73-84. México: Joaquín Mortiz, 1965.]

- 2004 [1944]. «Yo no invento nada». No son cuentos, 101-116. Madrid: Huerga y Fierro.

- 2007 [1942]. «Intervención del c. Max Aub, escritor español recién llegado de los campos de concentración en Djelfa y Argelia, en la sesión del 15 de octubre de 1942...». Dentro Eloísa Nos Aldás, «Presentación de las declaraciones de Max Aub en la "Asamblea contra el Terror Nazifascista"», 137-139. El Correo de Euclides 2: 136-139. —. 2015 [1944]. Diario de Djelfa, edición de Bernard Sicot. Madrid: Visor.

Aubrespy-Agullo, Suzanne. 2009. «Larrivée des réfugiés espagnols en Algérie: les camps d'internement (1939-1943)». Dentro Andrée Bachoud, y Bernard Sicot, dir., Sables d'exil. Les républicains espagnols dans les camps d’internement au Maghreb (19391945), 54-8o. Perpiñán: Mare Nostrum. [Número especial de Exils et migrations ibériques au $\mathrm{XX}^{e}$ siècle 3.]

Aznar Soler, Manuel, y José Ramón López García, ed. 2011. El exilio republicano y la segunda generación. Sevilla: Renacimiento.

Bachoud, Andrée. 2002. «Exilios y migraciones en Argelia. Las difíciles relaciones entre Francia y España». Ayer 47: 82-101.

Bachoud, Andrée, y Bernard Sicot, ed. 2009. Sables d'exil. Les républicains espagnols dans les camps d'internement au Maghreb (1939-1945). Perpiñán: Mare Nostrum. [Número especial de Exils et migrations ibériques au $x x^{e}$ siècle 3.]

Baldó García, Ricardo. 1970. Un cuento escrito en la arena. Alcoy: La Victoria.

-1972. Del negro al amarillo. Relatos del exilio. Alcoy: La Victoria.

-1977. Exiliados españoles en el Sahara, 1939-1943 (Un punto negro en la historia). Alcoy: La Victoria.

Balibrea, Mari Paz, ed. 2017. Líneas de fuga. Hacia otra historiografía cultural del exilio republicano español. Madrid: Siglo XXI.

Barciela, Carlos, y Carmen Ródenas, ed. 2016. Chemins de fer, chemins de sable. Los españoles del Transahariano. Alicante: Universitat d'Alacant. 
Beevor, Antony. 2017. La Segunda Guerra Mundial. Barcelona: Pasado y Presente. Beltrán Alcaraz, Isabel. 1989. «Stanbrook. Vivencias de un exilio». Dentro Asociación

Cultural Adagietto, Ciclos. Narraciones. Elche: Asociación Cultural Adagietto.

- 2016. Stanbrook. Vivencias de un exilio. Tavernes Blanques: L'Eixam.

Benaicha Ziani, Naimi, ed. 2016. Argelia. Una mirada desde las dos orillas. Alicante:

Universitat d'Alacant.

Benallou, Lamine. 2002. L'Oranie espagnole. Orán: Dar El Gharb.

Bennassar, Bartolomé. 2005. El infierno fuimos nosotros. La Guerra Civil española (19361942). Madrid: Taurus.

Beneyto Poveda, Milagros. 2014. Desterrados. La Eliana: Pasionporloslibros.

Bernabéu Vilaplana, Gerardo. 2006. «Diario (marzo-mayo 1939)». Dentro Miguel

Martínez López, Alcazaba del olvido. El exilio de los refugiados políticos españoles en Argelia (1936-1962), 217-228. Madrid: Endymion.

Bernabéu López, Gerardo. 2018. «Vivencias de la familia Bernabéu exiliada en Argelia».

Laberintos 20: 341-354.

Blanca, Antoine. 2002. Itinéraires d'un républicain espagnol. París: Bruno Leprince.

- 2014. Les trois voyages d'Abel, fils de républicain espagnol. París: Bruno Leprince.

Blanca, Antonio. 1991. «Cuaderno del destierro (fragmentos)», edición de Juan Martínez

Leal. Canelobre 20-21: 101-112.

- 2009. «Les cahiers d'Antonio Blanca», traducción de María Luisa Broseta.

Dentro Andrée Bachoud, y Bernard Sicot, dir., Sables d'exil. Les républicains espagnols dans les camps d'internement au Maghreb (1939-1945), 217-318. Perpiñán: Mare Nostrum. [Número especial de Exils et migrations ibériques au $x x^{e}$ siècle 3.]

- 2018. Diario de Antonio Blanca (campos de Argelia 1939), edición de Bernard

Sicot y Danae Gallo González. Alicante: Instituto Alicantino de Cultura Juan

Gil-Albert.

Bonmatí, José Fermín. 1992. Españoles en el Magreb (siglos XIX y XX). Madrid: Mapfre. Bouzekri, Nadia. 2011. «El teatro del exilio republicano en Argelia a través de

Solidaridad Obrera». Dentro Manuel Aznar Soler y José Ramón López García, ed., El exilio republicano y la segunda generación, 857-864. Sevilla: Renacimiento.

- 2012. «Derrotados, desterrados e internados. Españoles y catalanes en la Argelia colonial. ¿La memoria olvidada o el miedo a la memoria? (1936-1962)». Tesis doctoral, Universitat Autònoma de Barcelona. https://www.tdx.cat/ handle/10803/123296.

Cabezas, Felipe A. 1940. «Viaje épico. Los expatriados del Stambrook». Nuestra España 12: $55-66$.

Camacho, Marcelino. 1990. Confieso que he luchado. Memorias. Madrid: Temas de Hoy.

Camacho Samper, Yénia. 2016. De Orán y del regreso. Guillena: Atrapasueños.

Caroz, Christian, dir. 2007. Aurore, documental. Francia: Airelles Productions.

Castillo, Isabel del. 1954. El incendio. Ideas y recuerdos. Buenos Aires: AméricaLee.

Caudet, Francisco. 2005. El exilio republicano de 1939. Madrid: Cátedra.

Cazorla Herrero, Cristina. 2018. «La labor del consulado español en Orán (1939-1945)». Laberintos 20: 189-208. 
Charaudeau, Anne. 1992. «Les réfugiés espagnols dans les camps d'internement en Afrique du Nord». Hommes et Migrations 1158: 23-28.

Coale, Robert. 2010. «Alicante - Bel Abbès - Orán, un exilio inédito conjugado en primera persona: el diario de Lucas Camons Portillo». Dentro Bernard Sicot, coord., La littérature espagnole et les camps français d'internement, de 1939 à nos jours. Actes du colloque international 70 Años Después, 435-444. Nanterre: Centre de Recherches Ibériques et Ibéro-Américaines / Groupe de Recherches Résistances et Exils.

Cuesta Suárez, Nieves. 2009. Simplemente mi vida. Avilés: Azucel.

Déjeux, Jean, ed. 1985. Espagne et Algérie au $x X^{e}$ siècle. Contacts culturels et création littéraire. París: L'Harmattan.

Delhom, Joël. 2009. «Inventario provisorio de las memorias anarquistas y anarcosindicalistas españolas». Cahiers de civilisation espagnole contemporaine 4. doi: https://doi.org/10.400o/ccec.2677.

Dickson, Archibald. 199. Carta mecanuscrita al director del periódico londinense Sunday Dispach, firmada por A. D., master del SS Stanbrook, en Oran. 2-3 abr. https:// web.archive.org/web/20140802131238/http://www.elpais.com/elpaismedia/diario/ media/200904/01/espana/20090401elpepinac_2_Pes_PDF.pdf.

Dreyfus-Armand, Geneviève. 1999. L'exil des républicains espagnols en France. París: Albin Michel.

Dubosson, Christiane. 1985. «Laction franquiste en Oranie (1939-1942)». Dentro Jean Déjeux, ed., Espagne et Algérie au $x X^{e}$ siècle. Contacts culturels et création littéraire, 67-83. París: L’Harmattan.

Dulphy, Anne. 2009. «Centres d'hébergement et camps d'internement en Algérie (mars 1939 - mai 1940)», 99-117. Dentro Andrée Bachoud, y Bernard Sicot, dir., Sables d'exil. Les républicains espagnols dans les camps d’internement au Maghreb (19391945). Perpiñán: Mare Nostrum. [Número especial de Exils et migrations ibériques au $X X^{e}$ siècle 3.]

Epalza, Mikel de. 1985. «Max Aub et les écrivains espagnols “exilés” en Algérie». Dentro Jean Déjeux, ed., Espagne et Algérie au $x x^{e}$ siècle. Contacts culturels et création littéraire, 125-139. París: L'Harmattan.

Erll, Astrid. 2005. «Augenschaft und kulturelle Paradigmen: Zugänge zur Spanienkriegsliteratur». Dentro Bettina Bannasch y Christiane Holm, ed., Erinnern und Erzählen. Der Spanische Bürgerkrieg in der deutschen und spanischen Literatur und in den Bildmedien, 35-38. Tubinga: Gunter Narr.

Escribano Miralles, Pablo. 2012. «Refugiats del republicanisme espanyol a l'Àfrica del Nord durant la Segona Guerra Mundial». Segle XX 5: 63-83.

Escudero Galante, Francisco. 2002. Pasajero 2058. San Vicente del Raspeig: Club Universitario.

- 2006. El último barco del exilio. Barcelona: RBA.

Espinós Beviá, Antonieta. 2016. ¡Ya se va el vapor! 19 de marzo de 1939, Alicante-Orán. Aix-en-Provence: Verlaque.

Esteve, Arturo. 1957. Búsqueda en la noche. Buenos Aires: Nueva Era. 
Fernández Díaz, Victoria. 2009. El exilio de los marinos republicanos. Valencia: Universidad de Valencia.

Fernández Díaz, Victoria. 2018. «De la mar al destierro: el exilio de los marinos de la II República». Laberintos 20: 209-224.

Gaida, Peter. 2014. Les camps de Vichy en Afrique française du Nord. s.l.: edición del autor. Gallo González, Danae. 2016. «La “Transición” del consenso y su productividad cultural a partir del ejemplo de Internamiento y resistencia de los republicanos españoles en África del Norte». Dentro Marco Kunz, Rachel Bornet, Salvador Girbés y Michel Schultheiss, ed., Acontecimientos históricos y su productividad cultural en el mundo hispánico, 237-256. Zúrich: Lit.

_ 2017. «L'amour et l'écriture épistolaire dans les camps d'internement français en Algérie: l'exemple du journal d'Antonio Blanca». Dentro Marta Álvarez, Ida Hekmat y Sabine Lauret, ed., L'amour. Création et société, 81-91. París: Michel Houdiard.

—. 2018a. jRecuerda! Scribo ergo sum(-us). La escritura del yo de los exiliados políticos de la Guerra Civil en la Argelia colonial. Madrid/Fráncfort: Iberoamericana/ Vervuert.

2018b. «El exilio republicano en Argelia en los escritos (auto)biográficos de la familia Blanca». Laberintos 20: 225-244.

Gallo González, Danae, y Bernard Sicot. 2018. «Antonio Blanca: itinerarios», prólogo. Dentro de Antonio Blanca, Diario de Antonio Blanca (campos de Argelia 1939), 9-25. Alicante: Instituto Alicantino de Cultura Juan Gil-Albert.

García Durán, Juan. 1985. «El drama de Alicante». Historia 16 114: 11-14.

Gassó, Laura, ed. 2014. Diario de Gaskin. Un piloto de la República en los campos de concentración norteafricanos. Tavernes Blanques: L'Eixam.

—, ed. 2016. Operación Stanbrook. Homenaje a la memoria republicana. Tavernes Blanques: L'Eixam.

Gonzalez, Georges. 2003. Mais l'Algérie vivra toujours. París: L'Harmattan.

González Beltrán, Helia, y Alicia González Beltrán. 2006. Desde la otra orilla. Memorias del exilio. Elche: Frutos del Tiempo.

Grynberg, Anne, y Anne Charaudeau. 1994. «Les camps d'internement». Dentro Pierre Milza y Denis Peschanski, ed., Exils et migration. Italiens et Espagnols en France, 1938-1946, 139-161. París: L'Harmattan.

Guzmán, Eduardo de. 1973. La muerte de la esperanza. Madrid: Gregorio del Toro. [Reedición: 2006. Madrid: Ediciones Vosa.]

—.1976. «Agonía y muerte de la Segunda República en el puerto de Alicante». Triunfo 688, 3 abr.: 32-37.

Hammouche-Bey Omar, Rachida. 2015. La llegada de los refugiados republicanos españoles a Argelia según el diario francés 'Oran Républicain'. Orán: Archivo de la Frontera. http://www.archivodelafrontera.com/galeatus/la-llegadade-los-refugiados-republicanos-espanoles-a-argelia-segun-el-diario-francesoran-republicain-marzo-abril-1939-por-hammouche-bey-omar-rachida-de-launiversidad-de-oran/.

Hernández Tomás, Jesús. 1974. Yo fui un ministro de Stalin. Madrid: Gregorio del Toro. 
Hoyos Puente, Jorge de. 2017. «La historiografía sobre refugiados y exiliados políticos en el siglo xx: el caso del exilio republicano español de 1939". Ayer 106: 293-305.

Instituto Alicantino de Cultura Juan Gil-Albert. 1991. Alicantinos en el exilio, monográfico. Canelobre 20-21.

Jaeckel, Volker. 2015. «O porto de Alicante como lugar de memória de uma tragédia esquecida». Dentro XVI Congreso Internacional Associação Brasileira de Literatura Comparada (ABRALIC). http://www.abralic.org.br/anais/?p=40\&ano=2015.

Jiménez Margalejo, Carlos. 20oo. Los que teníamos dieciocho años. Madrid: Incipit.

- 2008. Memorias de un refugiado español en el Norte de África, 1936-1956. Madrid: Fundación Largo Caballero / Cinca.

Juliá, Santos. 2011. Elogio de Historia en tiempo de Memoria. Madrid: Marcial Pons.

Kateb, Kamel. 2007. «Les immigrés espagnols dans les camps en Algérie». Annales de Démographie Historique 113: 155-175.

Lázaro, Esther. 2018. «Djelfa en el epistolario maxaubiano». Laberintos 20: 245-258.

Lizcano, Conrado. 1989. «Exode et camps d'Afrique du nord: Témoignage de Conrado Lizcano». Bulletin du Centre International de Recherche sur l'Anarchisme (CIRA). Annexe de Marseille 29-30: 99-106.

—. 1991. «Crónica en vivo de los exiliados españoles en el Norte de África». Canelobre 20-21: 123-136.

López García, Bernabé. 2009. «El olvido del exilio de los españoles en el norte africano. La investigación sobre el exilio y la emigración de los españoles en Marruecos». Dentro Bernabé López García y Miguel Hernando de Larramendi, ed., Historia y memoria de las relaciones hispano-marroquies. Un balance en el cincuentenario de la independencia de Marruecos, 95-112. Madrid: Ediciones del Oriente y del Mediterráneo.

López García, José Ramón, y Juan Rodríguez, coord. 2017. El exilio republicano de 1939 y la segunda generación, monográfico. Ínsula 851.

Lluch-Prats, Javier; Evelio Miñano Martínez, y Javier Sánchez Zapatero, ed. 2016. El universo concentracionario, monográfico. Quaderns de Filologia 21.

Marco Botella, Antonio. 2007. La odisea del 'Stanbrook'. Memorias de un exiliado político. Zaragoza: Institución Fernando el Católico.

Martín Corrales, Eloy. 2012. «La emigración española en Argelia». AWRAQ 5-6: 47-62. Martínez Leal, Juan. 1986. «La guerra terminó en Alicante. La tragedia del puerto». Canelobre 7-8: 157-166.

- 2005. «El Stanbrook. Un barco mítico en la memoria de los exiliados españoles». Pasado y Memoria 4: 65-81.

—. 2018. «Los barcos del exilio en el norte de África (marzo de 1939)». Laberintos 202: $57-282$.

Martínez López, Miguel. 2004. Casbah d’oubli. L'exil des réfugiés politiques espagnols en Algérie (1939-1962). París: L’Harmattan.

- 2006. Alcazaba del olvido. El exilio de los refugiados políticos españoles en Argelia (1936-1962). Madrid: Endymion. 
Mas Galvañ, Cayetano. 2012. “Los ingenuos Quijotes de siempre”. El exilio republicano en Argelia a través de un epistolario». Dentro David Bernabé y Armando Alberola, ed., 'Magistro et amico'. Diez estudios en homenaje al profesor Enrique Giménez López, 249-277. Alicante: Universitat d'Alacant.

Menages, Àngela-Rosa, y Joan-Lluís Monjo. 2007. Els valencians d'Algèria (1830-1962). Memòria i patrimoni d'una comunitat emigrada. Picanya: Bullent.

Mera, Cipriano. 1976. Guerra, exilio y cárcel de un anarcosindicalista. París: Ruedo Ibérico. [Reediciones: 2006. Madrid: CGT / Solidaridad Obrera; 2011. Madrid: Asociación LaMalatesta.]

Mercadal Bagur, Deseado. 1983. Yo estuve en Kenadza. Nueve años de exilio. Mahón: edición del autor.

Moine, André. 1972. La déportation et la résistance en Afrique du Nord. 1939-1944. París: Éditions Sociales.

Morales Lezcano, Víctor. 1991. «Exilio y emigración al norte de África: reflexiones». Españoles en Francia, 1936-1946. Coloquio Internacional, 505-509. Salamanca: Universidad.

Morro Casas, José Luis. 2012. Campos africanos. El exilio republicano en el Norte de África. Madrid: Memoria Viva.

Muñoz Congost, José. 1989. Por tierras de moros. El exilio español en el Magreb. Móstoles: Tierra Madre.

Muñoz Congost. José. 1991. «Cultura en el exilio argelino». Canelobre 20-21: 137-142.

Murga, Julia, dir. 2015. Exilio español en campos africanos, documental. España: RNE. http://www.rtve.es/alacarta/audios/documentos-rne/131116-documentos-exilionorte-africa-2013-11-15t10-27-27727/2144666/.

Naharro Calderón, José María. 2010. «Para un diagnóstico traumático de las memorias concentracionarias españolas en Francia (1939-1944): de los campos metropolitanos y los de las colonias». Dentro Bernard Sicot, coord., La littérature espagnole et les camps français d'internement, de 1939 à nos jours. Actes du colloque international 70 Años Después, 89-110. Nanterre: Centre de Recherches Ibériques et IbéroAméricaines / Groupe de Recherches Résistances et Exils.

- 2017. Entre alambradas y exilios. Sangrías en las Españas y terapias de Vichy. Madrid: Biblioteca Nueva.

Nos Aldás, Eloísa. 2007. «Presentación de las declaraciones de Max Aub en la "Asamblea contra el Terror Nazifascista”». El Correo de Euclides 2: 136-139.

Oleza, Joan. 2011. «Ficción, historia y novela. La tragedia del puerto de Alicante». Revista Internacional de los Estudios Vascos. Cuadernos 8: 104-123.

Oliel, Jacob. 2005. Les Camps de Vichy. Maghreb-Sahara. Montreal: Éditions du Lys.

Ortega Bernabéu, Eliane. 2018. «Exilio republicano de 1939 en Argelia: los campos de concentración de Morand en Boghari y Hadjerat M’Guil en el Valle de la Muerte». Laberintos 20: 355-366.

Palacios Pilacés, Luis Antonio. 2010. La nación del olvido. El exilio republicano en el norte de África y los aragoneses. Zaragoza: Gobierno de Aragón. 
Palencia, Isabel de. 1946. Smouldering Freedom: The Story of the Spanish Republicans in Exile. Londres: Victor Gollancz.

Palomero, Josep. 2018. «Vida i exili dels germans Josep i Angelí Castanyer». Laberintos 20: 283-303.

Penef, Jean. 1988. «Le mythe dans l'histoire de vie». Sociétés 18: 8-14.

Rafaneau-Boj, Marie-Claude. 1995. Los campos de concentración de los refugiados españoles en Francia (1939-1945). Barcelona: Omega.

Roca, Paco. 2017. Los surcos del azar. Bilbao: Astiberri.

Rodrigo, Antonina. 1999. Mujer y exilio, 1939. Madrid: Compañía Literaria.

Rodríguez, Pilar. 1991. «La memoria del exilio y su representación en el testimonio oral». Dentro Españoles en Francia, 1936-1946. Coloquio Internacional, 391-396. Salamanca: Universidad.

Ros, Antonio. 1968. Horas de angustia y esperanza. México: Oasis.

-1976. Diario de un refugiado republicano. Barcelona: Grijalbo.

Ros i Martí, Germinal. 1989a. Un home del segle XX. Lloret de Mar: APAC.

- 1989b. «Els camps de concentració a l’Àfrica del Nord. Dels últims dies de la guerra civil a la vida concentracionària». Dentro Congrés Internacional sobre l'Exili als Països Catalans, 1939-1978. Barcelona: Universitat de Barcelona.

—.1989c. Anys negres. Crònica lliure dels anys de guerra, 1939-1945. Lloret de Mar: edición del autor.

— 1991. «El començament de l'exili. Anys negres. Crònica lliure dels anys de guerra (1939-1945)». Canelobre 20-21: 113-122.

-1999. Els meus primers 90 anys. Vivències. Lloret de Mar: APAC.

Rubio, Javier. 1977. La emigración de la Guerra Civil de 1936-1939. Madrid: San Martín.

Salinas, Alfred. 2008. Quand Franco réclamait Oran. L'Operátion Cisneros. París: L'Harmattan.

Sánchez Zapatero, Javier. 2009. El compromiso de la memoria: un análisis comparatista. Max Aub en el contexto europeo de la literatura del exilio y de los campos de concentración. Salamanca: Universidad de Salamanca.

- 2010. Escribir el horror. Literatura y campos de concentración. Barcelona: Montesinos.

- 2011. «La literatura testimonial española y la experiencia de los campos de internamiento franceses: una aproximación al corpus». Castilla 2: 215-232.

_. 2017. «Cartas y campos: la experiencia concentracionaria en el epistolario de Max Aub». El Correo de Euclides 12: 136-144.

Santacreu, J. M., ed. 2008. Una presó amb vistes al mar. El drama del port d'Alacant, març de 1939. Alicante: Universitat d'Alacant.

Santiago, Lucio, Gerónimo Lloris y Rafael Barrera. 1981. Internamiento y resistencia de los republicanos españoles en África del Norte durante la Segunda Guerra Mundial. Sant Cugat del Vallès: Rafael Barrera.

Santonja Cosnard, Aline. 1984. Les derniers jours de la République à Alicante: la «tragédie du port» (mars 1939). Nantes: Université de Nantes / Institut d’Études Hispaniques. 
Sella, Joan, dir. 2006. Cautivos en la arena. España: RTVE. http://www.rtve.es/alacarta/ videos/otros-documentales/otros-documentales-cautivos-arena/511486o/.

Serna Alba, Ricardo. 2016. Ricardo Serna Alba y 'El Liberal'. Exilio en Orán, edición de Ricardo Montes, José A. Sánchez y Enrique Serna. Murcia: Colegio de Periodistas.

Sicot, Bernard. 2000. «El lugar del Diario de Djelfa». El Correo de Euclides 3: 90-104.

- 2007. «Max Aub en Djelfa: lo cierto y lo dudoso». NRFH LV: 397-434.

. 2008. «Literatura española y campos franceses de internamiento. Corpus razonado (e inconcluso)». Cahiers de civilisation espagnole contemporaine 3. doi: https://doi.org/10.400o/ccec.2473.

- 2010. «Literatura española y campos franceses de internamiento. Corpus razonado (e inconcluso) III». Cahiers de civilisation espagnole contemporaine 6. doi: https://doi.org/10.400o/ccec.3171.

—. 2015a. «Campo de Djelfa: iconografía inédita». El Correo de Euclides 10: 130-144.

- 2015b. Djelfa 41-43. Un camp d'internement en Algérie. París: Riveneuve.

- 2018. «Campos de Argelia: el testimonio de Antonio Blanca». Laberintos 20:

303-314.

- ed. 2010. La littérature espagnole et les camps français d'internement. Nanterre: Université Paris Ouest - Nanterre- La Défense.

Soriano, Antonio. 1989. Éxodos. Historia oral del exilio republicano en Francia, 19391945. Barcelona: Crítica.

Stein, Louis. 1983. Más allá de la muerte y del exilio. Barcelona: Plaza \& Janés.

Torres, Rafael. 2004. Los náufragos del 'Stanbrook'. Sevilla: Algaida.

Vañó Mataix, Josep Lluís. 2018. «Vicente Mataix Ferre: la repatriación de un exiliado desde el norte de África». Laberintos 20: 367-372.

Vargas, Bruno. 1991. «Rodolfo Llopis: los primeros años del exilio». Canelobre 20-21: $171-184$.

-1999. Rodolfo Llopis. Una biografía política. Barcelona: Planeta.

- 2018. «Grandezas y miserias del exilio socialista en Argelia. El epistolario de Rodolfo Llopis y otros dirigentes socialistas alicantinos (1939-1947)». Laberintos 20: 315-328.

Vargas, Bruno, y Francisco Moreno, ed. 2007. Dramas de refugiados. Epistolario de Rodolfo Llopis y otros dirigentes socialistas alicantinos. Valencia: UNED.

Vilanova, Antonio. 1969. Los olvidados. Los exiliados españoles en la Segunda Guerra Mundial. París: Ruedo Ibérico.

Vilar, Juan Bautista. 1983. «La última gran emigración política española. Relación nominal de los militantes republicanos evacuados de Alicante por el buque inglés Stanbrook con destino a Orán en 28 de marzo de 1939". Anales de Historia Contemporánea 2: 273-330.

- 2006. La España del exilio. Las emigraciones políticas españolas en los siglos XIX y $X X$. Madrid: Síntesis.

—. 2007. «El viaje del Stanbrook y el exilio en Argelia». Dentro Ricard Torres y Miguel Ors, ed., Exilio y represión franquista, 86-95. Alicante: Prensa Valenciana. 
Vilar, Juan Bautista. 2007-2008. «Guerra civil, éxodo y exilio: la aventura del Stanbrook». Estudios Románicos 16-17: 213-227.

—. 2009. «El exilio español de 1939 en el Norte de África». En Abdón Mateos, ed., ¡Ay de los vencidos! El exilio y los países de acogida, 71-102. Madrid: Eneida.

Vilar, Juan Bautista, y María José Vilar. 1999. La emigración española al Norte de África (1830-1999). Madrid: Arco Libros.

Yazidi, Bechir. 2008. El exilio republicano en Túnez. Ferrol: Embora.

- 2018. «El exilio de los republicanos en África del Norte». Laberintos 20: 373-384.

Yousfi López, Yasmina. 2018. «La Argelia que miraba hacia España. El círculo de Emmanuel Roblès». Laberintos 20: 329-334.

Zerrouki, Saliha. 2011a. «El destierro o vivir en Argelia en Casbah d'oubli, de Miguel

Martínez López». Dentro El exilio republicano y la segunda generación. Sevilla:

Renacimiento. Dentro Manuel Aznar Soler y Juan Ramón López García, ed., El exilio republicano de 1939 y la segunda generación, 624-634. Sevilla: Renacimiento.

- 2011b. Max Aub y el exilio republicano español en Argelia. Argel: Office des Publications Universitaires.

. 2018. «Caminos de la interculturalidad en la literatura del exilio español en Argelia: la mirada del otro en la poesía de Max Aub». Laberintos 20: 385-392. 
